\title{
Model-based analysis of greenhouse gas emission reduction potential through farm-scale digestion
}

Tine L.I. Vergote, Wouter J.C. Vanrolleghem, Caroline Van der Heyden, Anke E.J. De Dobbelaere, Jeroen Buysse, Erik Meers, Eveline I.P. Volcke

Problem statement Can the carbon footprint of dairy farms be reduced through farm-scale anaerobic digestion?

Scenarios

(1)

Manure pit

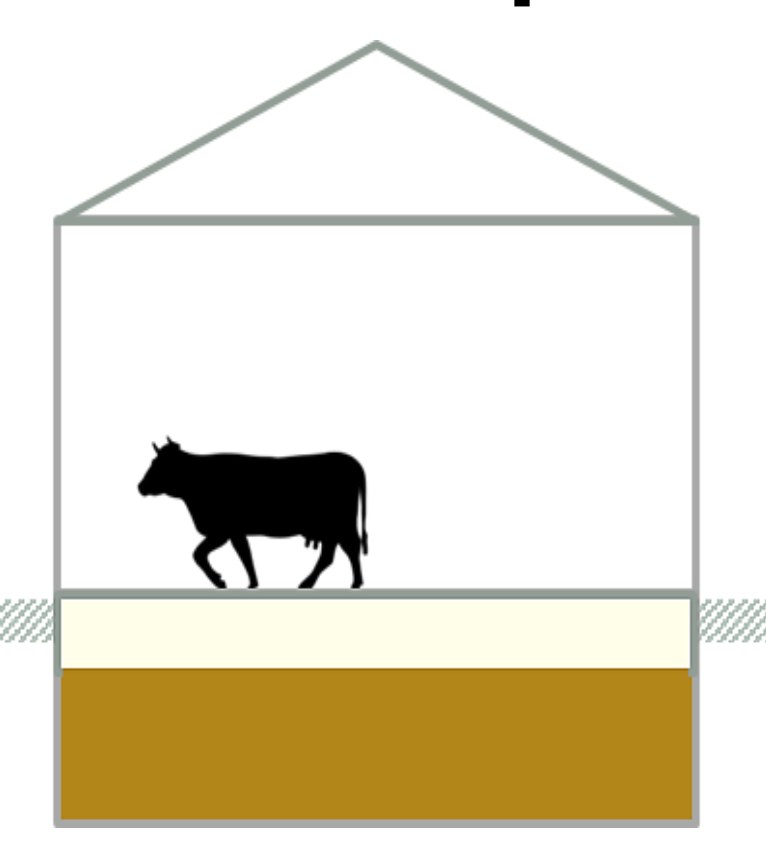

$\left\{\mathrm{CH}_{4}\right\}$

Long-term manure storage

Unwanted methane formation
(2)

Fresh manure digestion

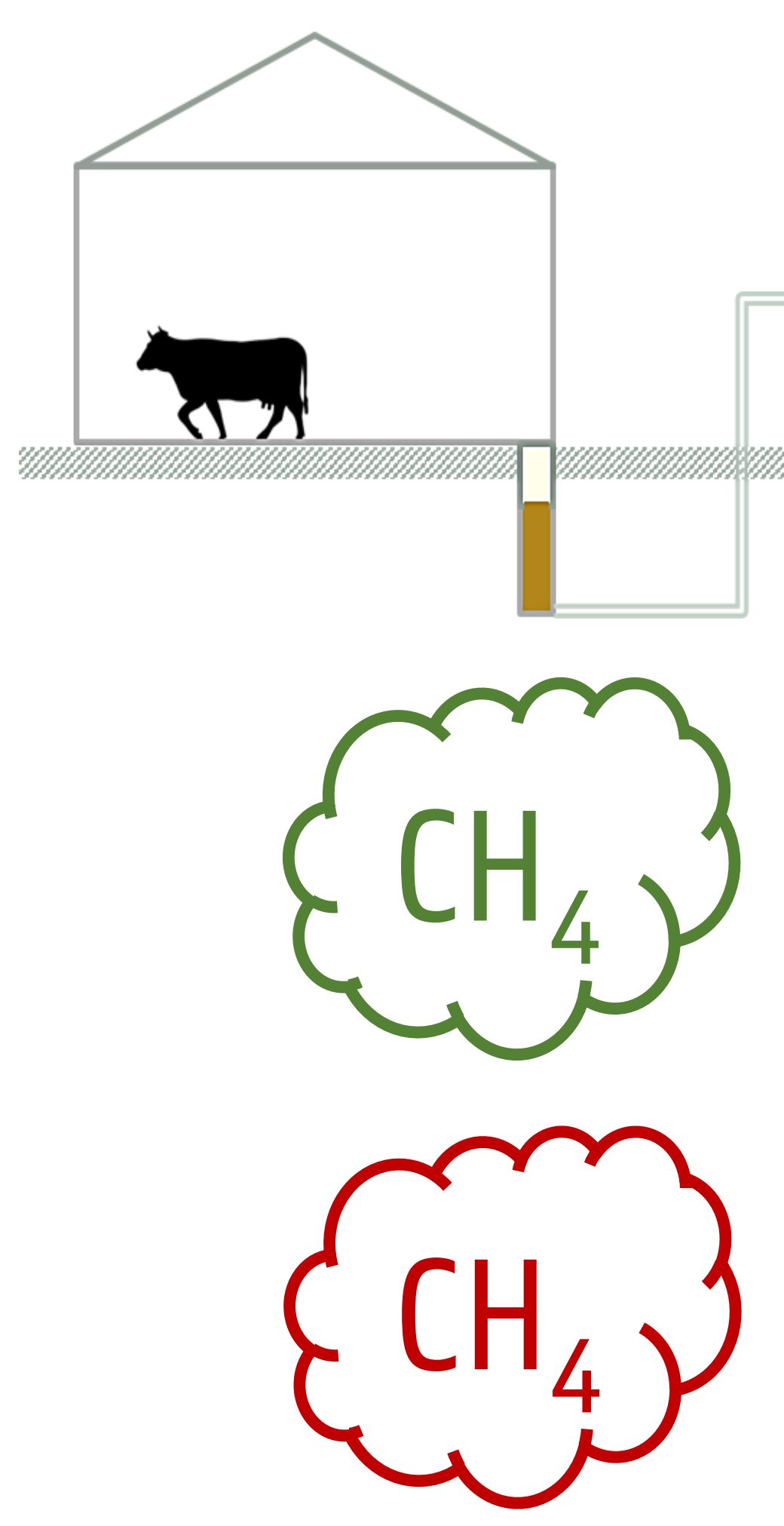

(3)

Pre-stored manure digestion

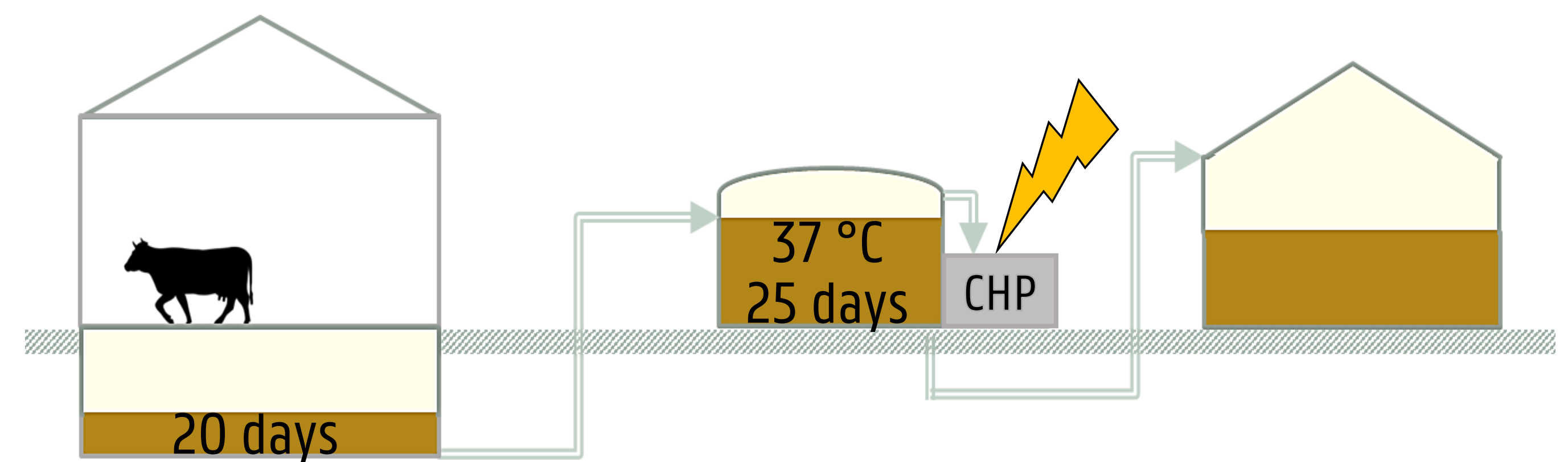

Farm-scale anaerobic digestion $=$ Renewable energy production from methane

BUT ALSO: Digester methane losses

Methane emissions from (pre-storage of manure and) long-term digestate storage

Method Fit-for-purpose anaerobic digestion model based on simplification of ADM1 assuming hydrolysis as the rate-limiting step. Inclusion of temperature dependency and constraints for storage for dynamic simulation of methane emissions and production.

Results

Carbon footprint ( $\mathrm{kg} \mathrm{CO}_{2}$-equivalents per $\mathrm{m}^{3}$ of manure)

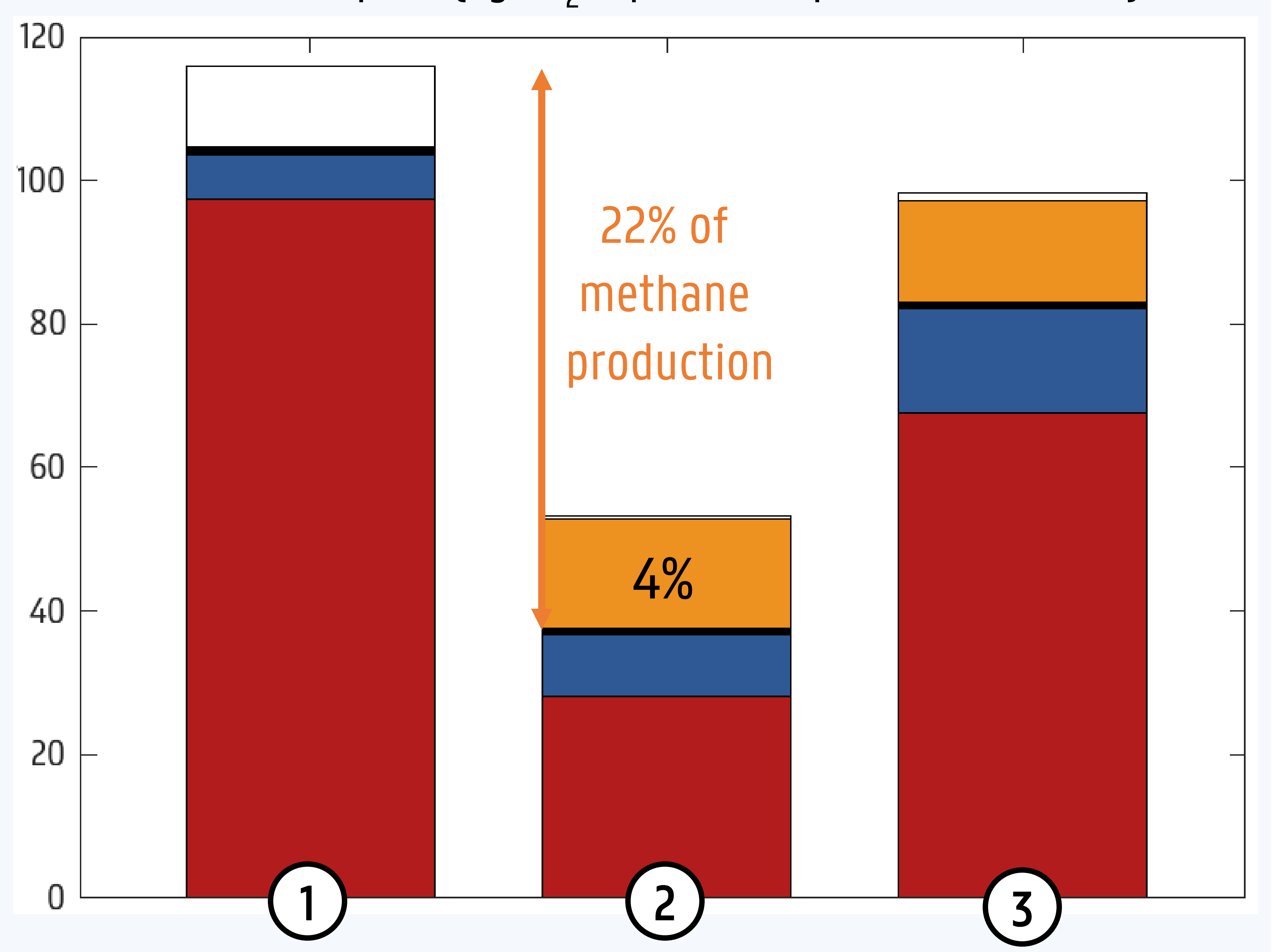

$\mathrm{CH}_{4}$ from storage (simulated) $\square \mathrm{N}_{2} \mathrm{O}$ from spreading

$\mathrm{N}_{2} \mathrm{O}$ from storage

$\mathrm{CH}_{4}$ from spreading

\section{Conclusions}

\section{Methane emissions from storage}

- Up to $70 \%$ reduction through fresh manure digestion at a digester retention time of 25 days

- Digestion of pre-stored manure or decrease in digester retention time = more methane emissions and less energy production from methane

\section{Carbon footprint of dairy farms}

- Over $80 \%$ related to methane emissions from manure storage, under relatively warm conditions and without controlled digestion

- Up to $50 \%$ reduction through fresh manure digestion (compared to a default dairy farm with a manure pit) assuming that digester methane losses are $4 \%$ of the methane production in the digester

- Possible reduction completely offset (no reduction compared to a default dairy farm with a manure pit) if digester methane losses are $22 \%$ of the methane production in the digester

Farm-scale anaerobic digestion can reduce methane emissions and the overall carbon footprint of default dairy farms with a manure pit if the digester is correctly dimensioned, properly managed and frequently monitored.

Further reading: Vergote et al. (2019). Model-based analysis of greenhouse gas emission reduction potential through farm-scale digestion. Biosystems Engineering, 181, 157-172. More information: Tine.Vergote@UGent.be

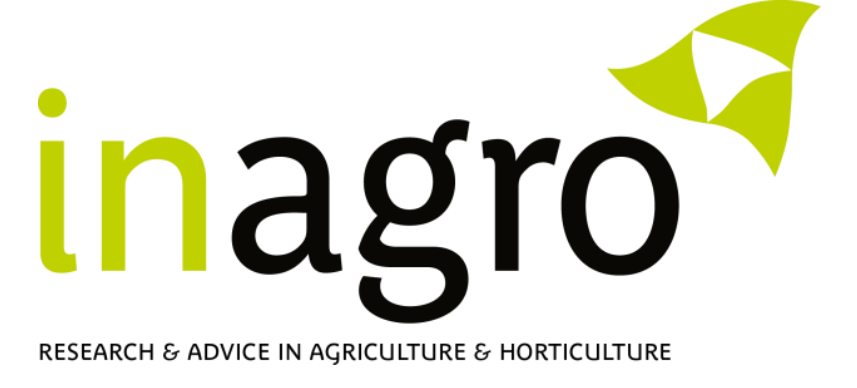

